\title{
A Mobile Telepresence Robot: A Case Study for Assessment of a Capstone Design Course
}

\section{Dr. Chan Ham, Kennesaw State University}

He is an Associate Professor in Mechatronics Engineering at the Kennesaw State University. He has over fifteen year experience in Mechatronics education and research.

\section{Ms. Jasmine Cherelle Washington}

Ms. Jasmine Washington graduated from Kennesaw State University, formerly Southern Polytechnic State University, with her bachelors of science in Mechatronics Engineering early 2014. Using the multidisciplinary nature of the program, Jasmine became highly interested in controls systems, mechanicals, as well as programs and project management. Since graduation, Jasmine has been working in a technical program management position at a company in Atlanta, GA that specializes in the use of ultrasonic technologies.

Mr. Steven Howell Sims

Dr. Kevin Stanley McFall, Kennesaw State University 


\title{
A Mobile Telepresence Robot: a Case Study for Assessment of Capstone Design Course
}

\begin{abstract}
This paper presents the assessment scheme used to evaluate that learning outcomes are met in the capstone design course for an undergraduate Mechatronics Engineering program. Included are sample rubrics used to evaluate the design-build-test model which introduces students to the design process frequently used in industry. Although the capstone course is populated with only Mechatronics Engineering students, all projects are interdisciplinary in nature as they include mechanical design, sensor data acquisition, programming, and physical control of actuators. A case study, the Mobile Telepresence Robot (MTR) is offered to provide an example of the scope required in these projects. Feedback from students both on the MTR team and other projects indicates the skills and practices learned in this course are directly applicable to the jobs they secure after graduation.
\end{abstract}

\section{Introduction}

Presented here are the assessment tools used to evaluate the learning outcomes for the capstone design course in a mechatronics engineering program. This course requires student teams to develop a working prototype including elements of mechanical design, sensor data acquisition, computer programming, implementation of a control system, and physical actuation of the system. In this manner, every project is interdisciplinary by definition, blending aspects of mechanical engineering, electrical engineering, and computer science. Indeed most teams choose to organize themselves where team member responsibilities are divided along these disciplinary lines. Each team of 3 to 5 members self-organizes and selects its own project, resulting in a strong degree of ownership for the project from the outset. Each project is assessed by a rigorous design review process in order to ensure the course learning objectives are achieved, which is described in Section II. Sections III-V then present details of one specific student project case study, the Mobile Telepresence Robot (MTR), providing a perspective for how a project unfolds to meet the course learning objectives. A conclusion, including student experiences with the course, appears in Section VI.

\section{Assessment of learning outcome and impact on students}

\section{Technical and professional learning}

The structured design review process described in detail in this section exposes students to systems engineering as it often exists on the job. This process involves sequential assignments which build from ideation through to implementation; this design-build-test model using sequential assignments has been identified as two of the five common elements of capstone projects at elite universities ${ }^{1}$. Class milestones are modeled on design review life cycles, such as those of NASA and other government entities, which are tasked with managing complex projects from basic concept to product completion ${ }^{2}$. For the mechatronics capstone design course, the instructor serves in the role of the reviewing organization to ensure project teams do not suffer scope creep that drifts too far from their agreed upon minimum success criteria. 
In the construction of a functional prototype, it is often the case that students choose to incorporate technologies into their project, other than those which were directly treated in prior degree program course work. In such case, a technical mentor can provide assistance with setup and direction with self-education tutorials. This approach provides the students with the experience, quite common in the mechatronics industry, of self-education to adapt to new technology product lines. Specifically with the MTR project described in detail, the microchip MPLAB development environment was used for MCU programming. However, it was also common to see other projects incorporate Raspberry Pi and Arduino control system components with access to tutorials and sample codes for those systems freely available on the web. Learning how to lean on self-education materials, set up development environments, and adapting reference designs was a key component of the professional development educational goal.

\section{Learning outcomes}

The Mechatronics System Design course aims to address the following learning outcomes:

[a] Apply mathematics, science, and engineering to a project.

[b] Design systems, components and processes to meet desired needs within realistic constraints such as economic, environmental, social, political, ethical, health and safety, manufacturability, and sustainability.

[c] Function in multi-disciplinary teams.

[d] Identify, formulate and solve engineering problems (analysis, design, verification, validation, implementation, application, and maintenance of a system).

[e] Understand professional and ethical responsibility.

[f] Learn effective communications - oral and written.

[g] Be able to use the techniques, skills, and modern engineering tools necessary for engineering practice.

In the following description of how projects are documented, activities addressing each learning outcome are marked with the appropriate letter in brackets, i.e. [a] for applying mathematics, science and engineering to a project.

\section{Project Proposals}

The project teams, usually consisting of groups of 3-5 students [c], convene to choose a project which is an integrated mechatronics system. Emphasis on group projects is another common element of capstone projects at elite universities ${ }^{1}$, and teams of 3-4 students are deemed optimal ${ }^{3}$. Additionally, student engagement has been shown to increase when students are allowed to choose their own projects ${ }^{4}$. The selected mechatronics system project must include the mechanical design of a physical structure, data acquisition of sensor output, programming a computer and/or micro-controller, and an actuator control system [a]. Although Mechatronics Engineering is technically mono-disciplinary as a free-standing program, the requirements for acceptable capstone projects ensures teams work across multiple disciplines [c] including computing, mechanical engineering, and electrical engineering, something increasingly popular for capstone projects ${ }^{5}$. The MTR project in particular meets these requirements by designing an aluminum structure, implementing a sonar sensor array and camera, programming a small 'netbook' laptop computer with integrated micro-controllers, and developing computer-based control software for the traction motors and RC-style servo motors [g]. 
As part of every proposal, teams also develop technical specifications which are realistic given the nature of the project [b]. For example, the MTR was intended to be able to navigate hallways at walking speed and be easily picked up and moved. This sets early constraints on the physical dimensions and power requirements [a] to which the team would refer during component selection trade studies later in the design process.

A specific minimum success criteria is also chosen, which clearly defines the minimum performance which the constructed prototype design is expected to demonstrate at the end of the course [b]. The MTR had the minimum success criteria of navigating remotely through a short course of hallway and entering a room, while also demonstrating the ability to stop, without human input, if an obstacle was in its commanded path.

The instructor evaluates the project proposals and approves or enhancements or alternatives to ensure the right depth of coverage as well as verify the feasibility of the project cost and time constraints of a single semester course $[b]$. The instructor verifies that key engineering works will be included through the development of the system: analysis, simulation, construction, and testing to validate the analysis and simulation methods [d].

\section{System Concept Review (SCR) and System Requirements Review (SRR)}

SCR focuses on design objectives, requirements definition, design concepts, project feasibility, and overall schedule and budget. It is held to assure that the objectives and requirements of the item being designed are understood and that the proposed approach will meet these requirements. As this is for a single semester course, the SCR is combined with the next level of review.

SRR is a formal review conducted to ensure that system requirements have been completely and properly identified. It ensures that the system under review can proceed into initial systems development. The students present the SCR and SRR in a combined presentation to the class and instructor [f], providing visual aids for design sketches, high-level block diagrams, and the like².

\section{Preliminary Design Review (PDR)}

PDR written report [f] reviews the initial design of subsystems, interfaces, and configuration items relative to the design requirements. Particular emphasis is on project management and systems engineering [d]. This gives the instructor a mid-course opportunity to determine completeness and consistency with standards, raise and resolve any project-related issues [a], and to identify and mitigate project, technical, and even group dynamic issues ${ }^{2}[\mathrm{e}]$.

\section{Critical Design Review (CDR)}

CDR written report [f] reviews of the design at the $90 \%$ completeness level. Release of design drawings, assessment of the design maturity, risk [e], and compliance with requirements are all handled prior to prototype hardware build. Updated system and subsystem analyses are included, which are used to determine the maturity of the design is appropriate to support proceeding with full-scale fabrication, assembly, integration, and testing².

\section{Final Presentation and Demonstration}

The final presentation is performed with each team member participating and providing a synopsis of the development of the prototype [f]. It is performed for attendees including 
outsiders who have not seen any prior presentations, which helps to guide the presentation to be more digestible to a wider audience.

The presentation is followed by a live demonstration of the working prototype. The prototype must perform at least those functions defined by the minimum success criteria. In the case of the MTR, it was successfully navigated through a hallway and into a room, with many bystanders observing. A team member also walked in front of the MTR as it was moving to demonstrate the automated collision avoidance feature.

\section{Technical Logbook}

A hand-written technical logbook is maintained by each student. The instructor evaluates the logbook in the middle and at the end of the semester. It is expected to include any technical analysis, calculation, designs, drawings, and any other information pertinent to the design process and evolution of the project [d]. The log book is a major accountability tool to ensure continued regular involvement in the team project. Additionally it can become a valuable reference source to the student during the project. For the MTR project, the notebook was such a valuable resource, containing, for example, important but hard to find datasheet information such as microcontroller registers. At least one MTR team member continues the practice of maintaining a technical logbook for engineering work since it was so useful.

\section{Weekly Group Meeting Progress Reports}

A certain number of hours working together as a team was a requirement of the course [c]. This included a team meeting in which all members must be present. The goal was to organize the team and manage the project in a timely manner, as well as provide accountability to the instructor. A weekly team meeting report format was provided to each team. This included a short-, mid-, and long-term task listing. Completed, on-going, and new major tasks were listed, with target dates for new tasks. Meeting minutes were also included for accountability, including time, venue, attendees, primary agenda, and action items.

\section{Final Report}

In the final report [f], a comprehensive high-quality description of the project is compiled. It includes the scope, importance of project/system, major achievements and lessons learned. It also chronicles the development cycle, including component trade studies, schedules, and team member contributions.

\section{Mechatronics System Prototype Demonstration}

The construction of a working prototype is a requirement of the course. The hands-on time is important in giving the students a taste of the unexpected which does not come from analysis of datasheets. Sensor interference, power loading effects, software debugging [a], and even off the shelf component ordering lead times were all confounding issues that the MTR team faced. All of these are real-world considerations that even the idealized design engineer should be aware of when designing a product for market.

\section{Grading}

The grading scheme for the course below holds students accountable for documenting every step of the process to ensure all learning outcomes are met. The numerous writing and oral reviews of 
the team's work ensure projects stay on track and properly document how each of the learning outcomes is met. Each grading component is evaluated using either a rubric matrix (see Appendix A for samples) or a detailed evaluation rubric (see Appendix B for sample).

1. System Concept Review (SCR) \& System Requirements Review (SRR) Presentation 5\%

2. Preliminary Design Review (PDR) Presentation \& Written Report $10 \%$

3. Critical Design Review (CDR) Presentation \& Written Report / Final Presentation and Written Report 25\%

4. Completion and Demo of a Prototype $30 \%$

5. Notebook, Weekly Progress Report, and other Presentations/Exams, Attendance and other assignment $20 \%$

6. Performance Evaluation by Peer $10 \%$

While all learning outcomes are important, effective communication [f] is of particular emphasis $^{11}$. This ensures that engineering students, who by definition have strong technical backgrounds, are also capable of properly documenting their work writing and effectively presenting the material.

\section{Mobile Telepresence Robot Project Overview}

This project develops a working prototype of a mobile telepresence robot (MTR) as a case study for a successful capstone design project in an undergraduate Mechatronics Engineering curriculum. An aluminum body was be built to provide a stable framework in which to house the different components of robot. The mobile robot platform integrated a video camera and ultrasonic sensor array to provide users the ability to remotely connect and navigate in a different environment. The camera is attached to the body via two servo motors to provide pan and tilt capability to the user. A Windows netbook is used to process user commands and control each of its components.

The primary objective of this project was to complete the design, build, and programming a mobile telepresence robot in the span of one scholastic semester that would have the ability to complete the following: the telepresence robot will be operated via a web based user interface for a distance of approximately 100 feet into a demo room (doors propped open) in no more than 5 minutes. While the robot is in motion, an obstacle will be suddenly placed in its path. The telepresence robot is tasked with coming to a stop not more than 2 feet away, even while forward motion command is being given by user.

Design began with determining structure specifications and performing trade studies to decide which components would be utilized to make the telepresence robot as successful as possible.

- 2-D maneuverability over typical office flooring

- Remote controllable by a user with a web browser

- Safe operational constraints in the event of network errors

Specifications for the mobile telepresence robot's design are based on the desire to make a robot sufficiently large to interact with humans, sufficiently small enough to navigate normally-sized 
hallways, and that had a platform substantially sturdy and robust. The robot needed to be capable of driving forward at approximately $4.0 \mathrm{ft} / \mathrm{s}$. The robot will also be expected to be able to turn inplace at 60 degrees per second and halt motion if impending collision is detected by the onboard sensors. This should allow for the robot to navigate through doorways and around corners while still being able to avoid a collision with both fixed and moving objects.

\section{Development of the system}

The mobile telepresence robot is a mechatronic system composed of mechanical parts, sensors, actuators, and computer systems. A block diagram of the MTR system, appearing in Figure 1, gives an overview of key components and subsystems.

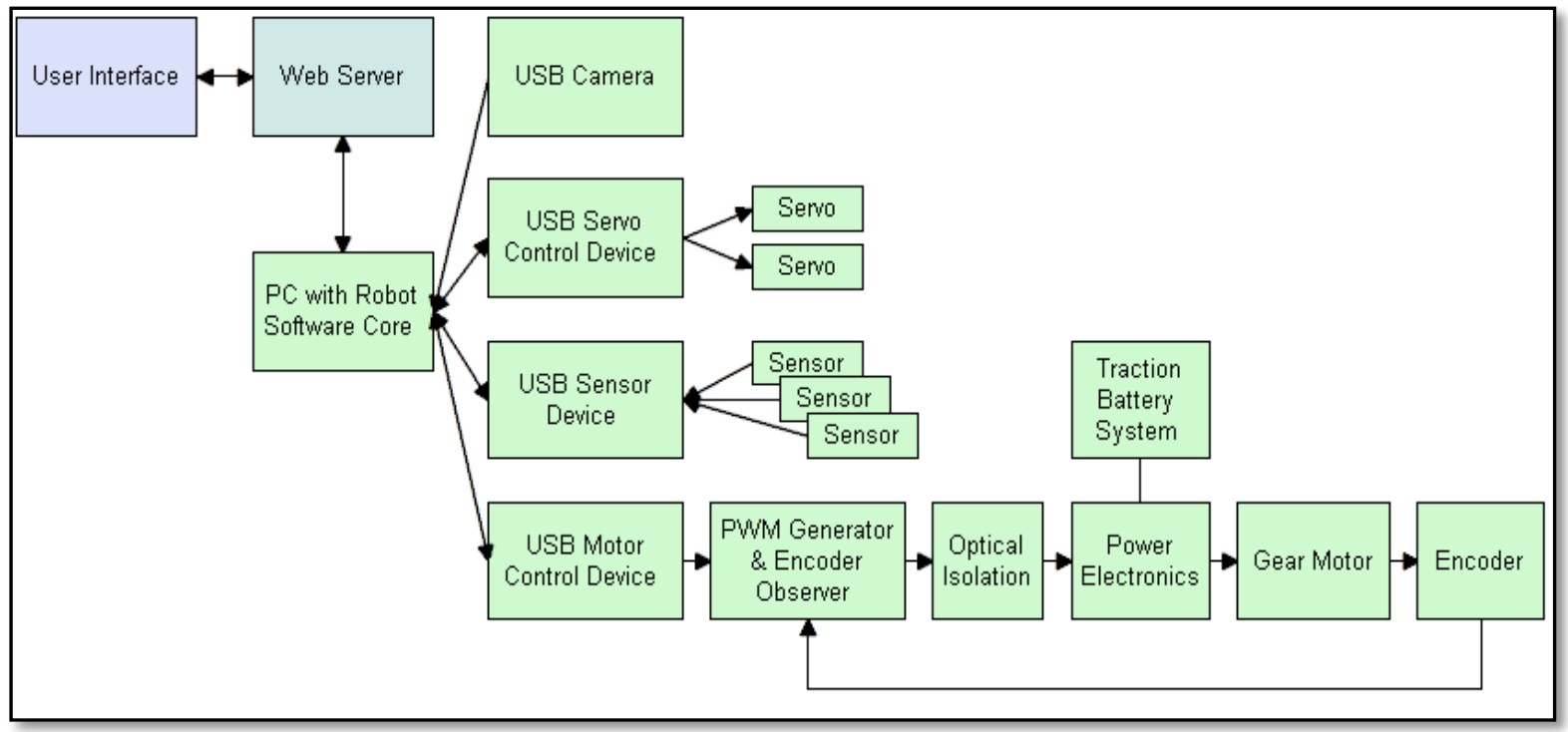

Figure 1: Mobile telepresence robot block diagram

Key components include:

- Structure: An aluminum frame will be designed to carry loads imparted by system components

- Sensors: A sonar sensor array will provide signals to a microcontroller, which is used by the core robot software to provide collision prevention

- Actuators: Two wheels are motor-driven for locomotion and servo motors are used to provide pan/tilt capability for a camera

- Computer Systems

o Web server will present user interface and negotiate connections

o Robot computer report status, processes commands, and interpret sensor data

o Microcontroller subsystems interface with physical devices and communicate with robot's computer

\section{Structural Frame}

The MTR's structure must be sufficiently strong to support at least $150 \mathrm{~N}$ of force due to the mass of its components. This is based on the specification of a system maximum weight of $35.6 \mathrm{lbs}$. It is assumed that distribution of component weight will be approximately evenly 
distributed over the structure. Aluminum was chosen as the build material for its light weight and ease of manufacture as shown in Figure 2.
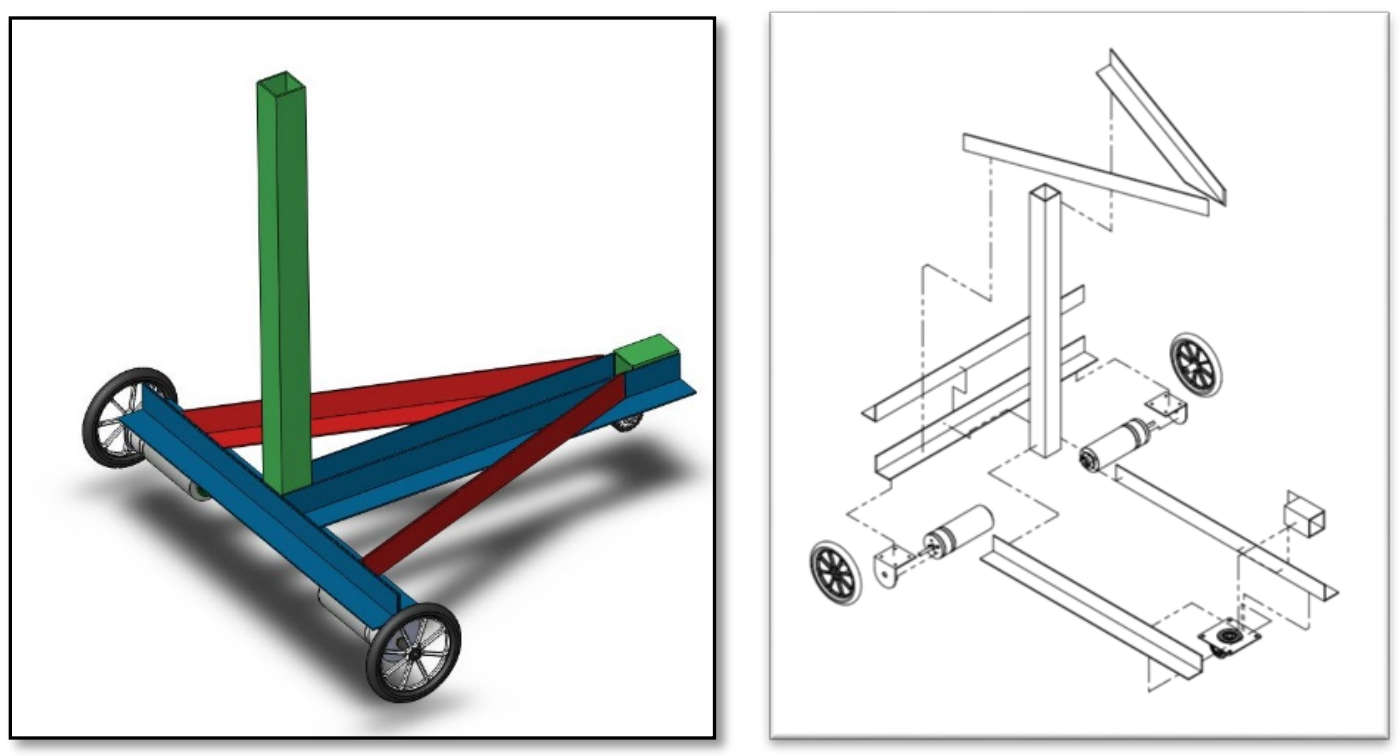

Figure 2: MTR Frame and its Exploded View

\section{Sensors}

The sensor array for the mobile telepresence robot would allow for obstacle detection and avoidance. It was decided that ultrasonic sensors would be utilized as opposed to infrared sensors due to the wider range and reliability of detection. Ultimately, the mobile telepresence robot would use a slightly more expensive MaxSonar-EZ1 ultrasonic sensor as part of its sensor array.

\section{Controllers}

The microcontrollers are critical to the function of this robot, as they provide an interface between the core software and all external hardware. This telepresence robot's design relies on three USB devices: USB Sensor Device, USB Motor Device, and USB Servo Device. A microcontroller with many features and capabilities was favored strongly. It was decided to move forward with the PIC18F4550 as it met most of the criteria needed for this project as well as being the only one in this list that will support USB out-of-the-box ${ }^{5}$.

The Olimex PIC-USB-4550 development board was also used as a reference design for the baseline circuit of each of the mobile telepresence robot's USB devices ${ }^{6}$. The Olimex circuit schematic was modified to reduce the circuit to only necessary components. A circuit was designed in Copper Connection software using the modified circuit schematic. A surface mount device form was selected to reduce overall size and simplify prototyping. A laser printer toner transfer process was used to mask a copper-clad board. Etchant was then used to remove unmasked copper. The board required a few fixes to bridge traces with solder, but the result exceeded expectations.

\section{Motor Controller}

An off-the-shelf motor controller was chosen for the telepresence robot in lieu of developing one for the project. Time constraints and lack of published information in the motor data sheets were 
driving forces behind this decision. The RoboClaw 2 channel 15A motor controller was an inhouse part which met the requirements for current capacity and offered several signal options to interact with the USB Motor Device?.

\section{Software}

The software for the mobile telepresence robot can be separated into two areas: microcontroller firmware and PC software. The microcontroller firmware is programmed in $\mathrm{C}$ and encompasses the logic and functions necessary for the PC software to interact with hardware components on the robot. The PC software is programmed in C\# and can further be separated into core logic, web server, and the user interface. All software is developed in a Test Driven Design (TDD) approach. In this manner, tests for each piece of modular functionality is first defined and software is written to meet test requirements.

\section{Microcontroller Firmware}

Each microcontroller utilizes code from the Microchip Library for Applications (MLA). Processing of low level USB communications is handled in this library ${ }^{8} .64$ byte data packets are sent and received between the device and the host. The microcontroller must run a function USBDeviceTasks at least every 1.9 ms to maintain connection with the host ${ }^{9}$. Particulars of this function are abstracted away from the application via the MLA, but it is high priority code and timing must be considered. Based on prior timing tests, it was possible to perform analog to digital conversion on all 13 channels of the microcontroller between calls to USBDeviceTasks. A call to processUsbCommands processes waiting command packets from the USB host. In the MTR Test App, these may contain various test routines, but primarily it is a request to receive the latest ADC data stored after each conversion.

\section{PC Software}

The PC software is designed to run on the MTR's Windows Netbook. Programmed in C\#, it utilizes Microsoft's .Net Framework 4.0 for many aspects of the application. Image capture functions are dependent on the Direct Show library, and audio capabilities have been initially scoped to use the NAudio library. It also utilizes the WFF USB Generic Communications framework for communication with each USB device. The functions of the PC software are encapsulated in the segment of the system block diagram as shown in Figure 3.

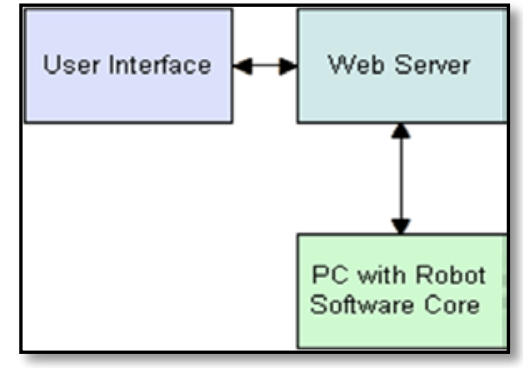

Figure 3: PC Software Blocks

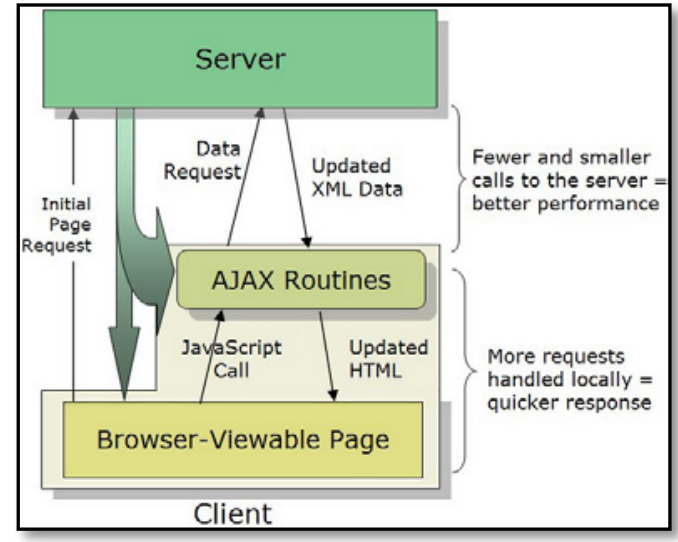

Figure 4: Client-Server Interaction with AJAX 
The web server component implements an HttpListener class from the .NET Framework and responds with asynchronous javascript and XML, a technique known as $\mathrm{AJAX}^{10}$. The user interface is a JavaScript and DHTML single page application which is updated dynamically. The client-server interaction is shown in Figure 4.

The robot core software is responsible for interacting with the USB devices and executing code which includes control laws, such as collision prevention that overrides user commands if sensors indicate an obstacle. It receives commands from the user via the web server, and reports status to the user via the web server. It is responsible for translating high level user commands into lower level command codes and data arguments for the USB devices to act on.

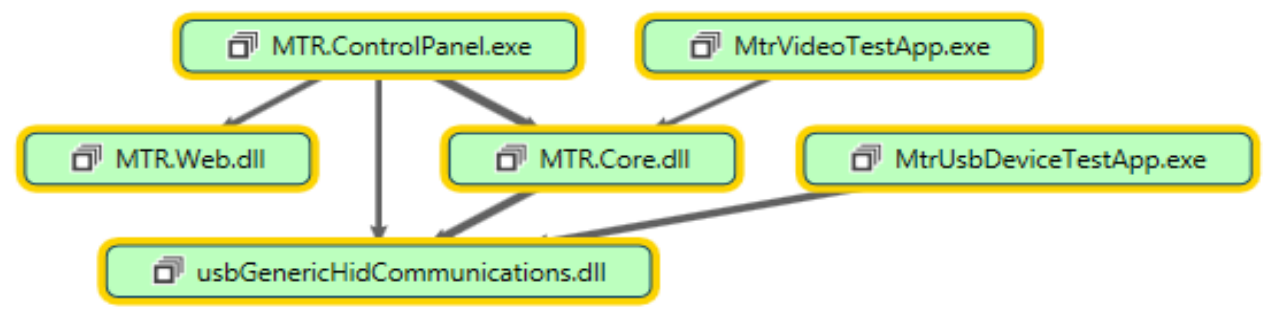

Figure 5: MTR PC Software Binaries

Software binaries are shown in Figure 5. This is the high-level view that shows code which will be deployed to the robot. Finally, all primary components of MTR were added to the frame as shown in Figure 6.

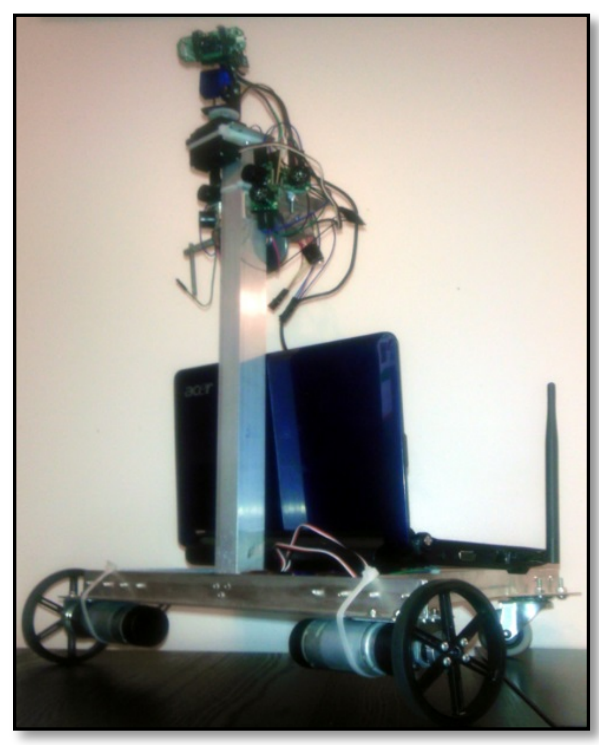

Figure 6: Working Version MTR

\section{Analysis, Simulation and Test}

The design verification approach relied heavily on testing each modular component and function of the system. In addition, the MTR development and testing setup is shown in Figure 7. 


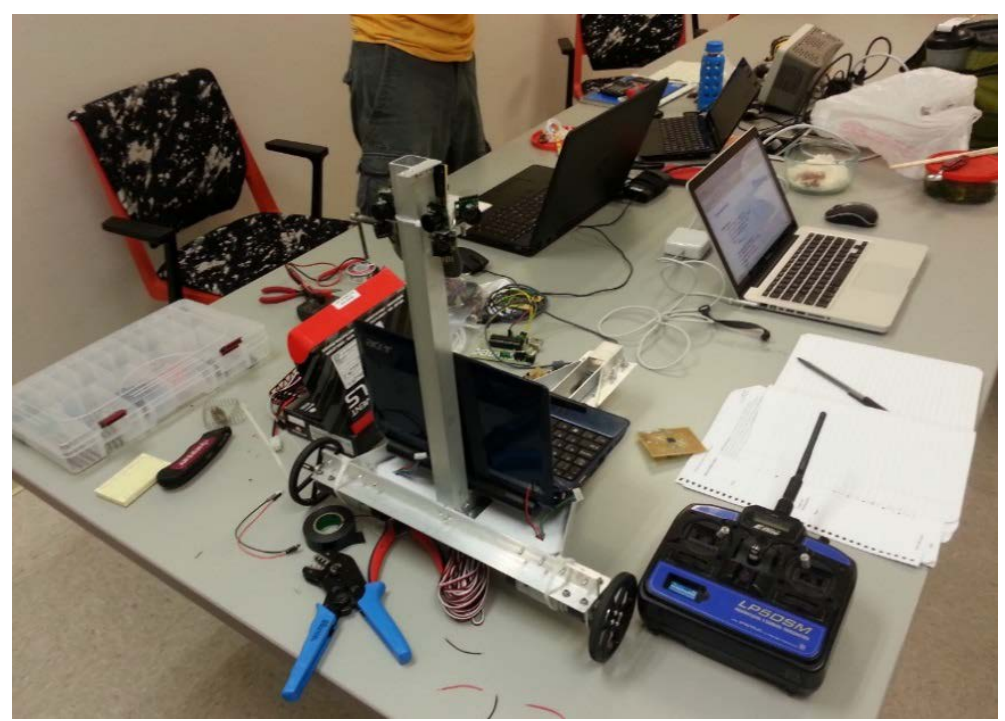

Figure 7: MTR Development and Testing Station

\section{Frame}

The frame incorporates two L-shaped beams with the intention on distributing force evenly throughout the frame.

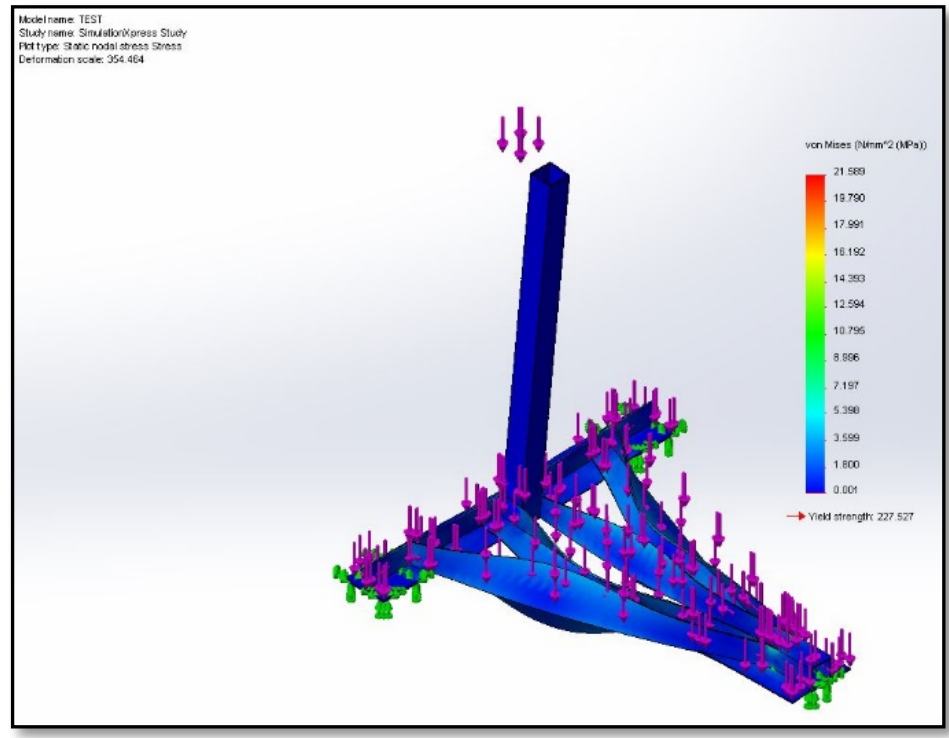

Figure 8: Von Mises Stress on structural frame

In Figure 8, a force with magnitude of $150 \mathrm{~N}$ is applied to the whole frame. The test results indicate this frame body distributes load uniformly and adds stability. Additional simulation tests provided a minimum factor of safety of $\sim 10.54$, implying that the body of the robot would be structurally sound under an applied force of $150 \mathrm{~N}$.

\section{Microcontroller USB Devices}

Timing of the microcontroller's functions required close consideration. The USB specification requires many functions to maintain communication with the host system. It is necessary to run 
an USBDeviceTasks function at least every $1.9 \mathrm{~ms}$. This places a lower limit on the clock speed and efficiency of application code on the device.

Assuming the time to toggle a digital output pin to be negligible and subtracting the time required to perform the minimum necessary USB communications and control structure ( $\left.\mathrm{t}_{3}\right)$ from the results of the $4^{\text {th }}$ test to acquire and store an analog signal $\left(\mathrm{t}_{4}\right)$ gives the required time to complete and store one analog to digital conversion, and also converting to frequency

$$
\frac{1}{\left(t_{4}-t_{3}\right) / 10^{6}}
$$

The result is a maximum analog sampling rate of $28 \mathrm{kHz}$. This placed a limit on the usable combined sample rate of any sensors to be evaluated for the system. High cost, faster rate sensors would be underutilized, and thus trade studies on sensors was restricted to lower cost parts as a result.

\section{Motor Control}

In Figure 9, motor controller test setup with gear motor to test and analyze both components. Radio control was used to send speed control signals to each channel of the motor controller ${ }^{11}$. The motor and controller results, per channel, with $14.4 \mathrm{~V}$ battery system:

- 2.56A stall current, $100 \mathrm{~mA}$ no load current, and steady-state current is $140 \mathrm{~mA}$

- $\quad$ Forward speed of $2.07 \mathrm{ft} / \mathrm{s}$.

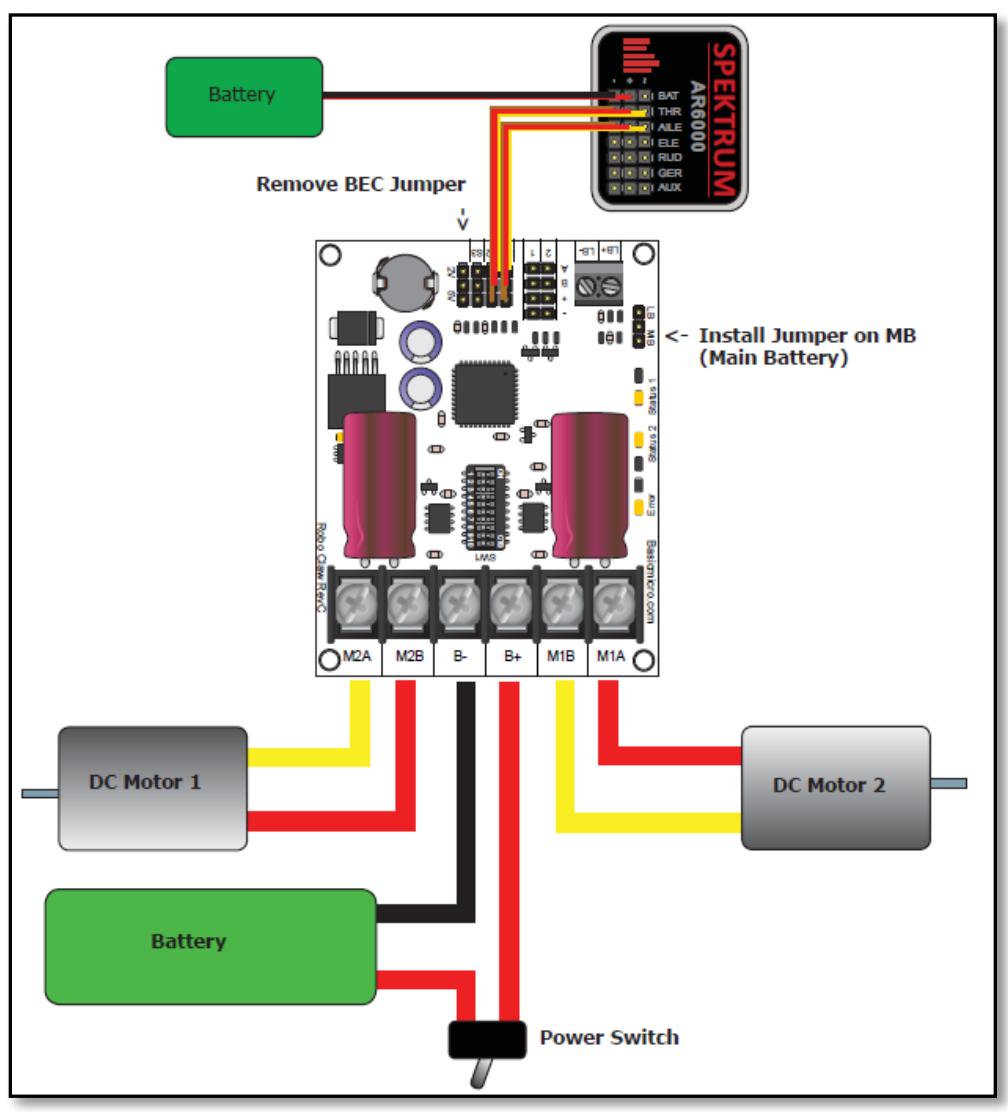

Figure 9: Motor Controller Test Setup with RC Controller 
Signals were also generated by microcontroller firmware. These were of a modified PWM form, like that of typical hobby radio control signals. An oscilloscope was used to test and modify timings in the firmware to produce a pulse in the range of 1 to 2 milliseconds, which is a full reverse to full forward motor control signal.

Direct swap-in of radio control is retained for test and troubleshooting. Also an RC multiplexer may be incorporated to provide an additional external manual override of motor controls.

\section{Sensors}

Testing of an individual MB1010 sensor was found to be satisfactory. However, it was still necessary to increase the coverage area for the intended use beyond what was possible with a single sensor. Image editing software was used to perform rotation transformations to approximate the angles from the published diagram. At ranges within 5 feet, the pattern is approximately 40 degrees wide. This would only provide straight-line collision prevention, and only if objects were no closer than 3 feet and static. An array of multiple sonar sensors

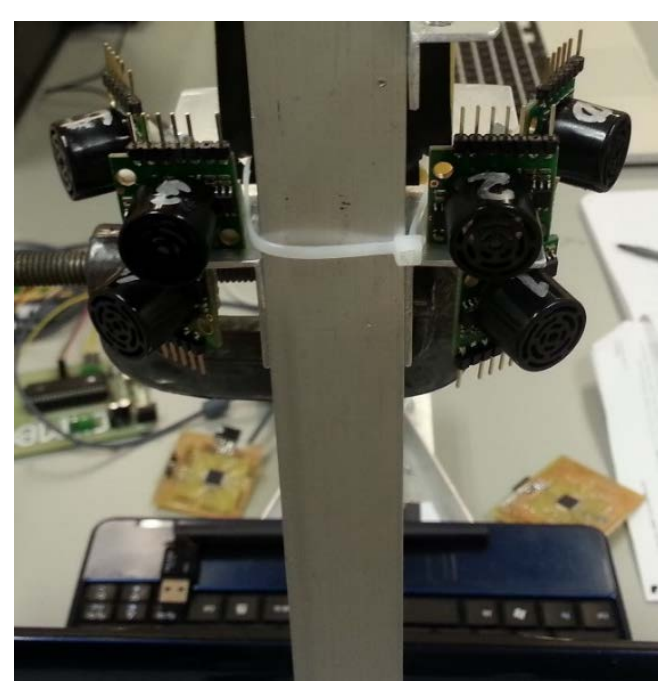

Figure 10: Sonar Sensor Array would allow detection at close range and over a wider area. It was found that an even number of sensors would allow a symmetry and recessed mounting to help protect the sensors. In total, six sensors were purchased and mounted to the structure, as shown in Figure 10.

Operating in the synchronized mode provided time isolation from adjacent sensors' ranging and allows for distance resolution between each at the cost of reduced sample rate for the area covered by a given sensor. With an array of six sensors, using the published sample rate of 20 $\mathrm{Hz}$, the rate per area covered is 20/6, or $3.333 \mathrm{~Hz}$. This was suitable with the robot's forward motion specified at $4.0 \mathrm{ft} / \mathrm{s}$, as it would cover no more than $1.2 \mathrm{ft}$ between sensor ranging. This would provide adequate time to respond within the bounds of the minimum success criteria.

\section{Sonar Triggering Device}

A notable addition to the initial proposed design for the telepresence robot was the inclusion of a separate device to trigger ranging of each sonar sensor ${ }^{12}$. Controllable independent triggering of individual sensors in the array was indicated following the testing of multiple sonar sensors.

Microcontroller triggering would allow this control. This would also allow possible expansion of features, such as switching between sequential and synchronized modes as the environment and functional needs might dictate, as well as being able to reduce power dissipation while MTR was idle and sonar ranging was not required.

A PIC16F688 microcontroller was selected for the sonar triggering microcontroller ${ }^{13,14}$. The choice was primarily due to the in-house availability. The controller's internal oscillator is capable of $8 \mathrm{MHz}$ operation, which exceeded that required for the sensors and kept the circuit simplified. Six digital I/O pins are available for each of the six sensors. LED indicators were later included on each pin for visual confirmation of the correct triggering behavior. 


\section{PC Software}

The robot's core software underwent development in a Test Driven Design approach. Staged testing was performed for each functional area. Critical elements of the software were tested and proven most visibly in the MTR Test App as shown in Figure 11, which was used to acquire and visualize sensor data.

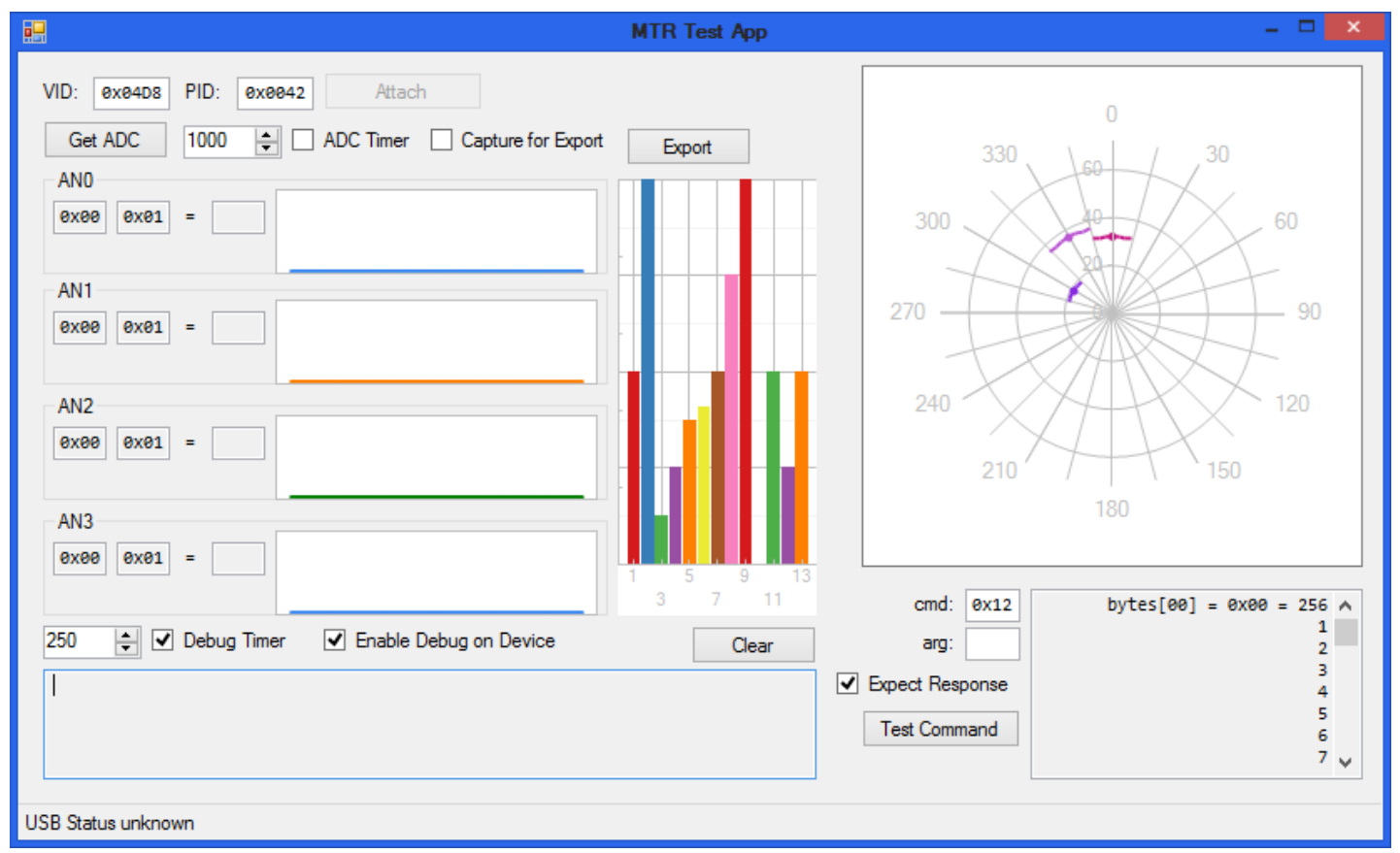

Figure 11: MTR Test App

\section{Conclusion}

Details of the Mobile Telepresence Robot (MTR) project illustrate how interdisciplinary these mechatronics capstone projects are, with significant components of mechanical design, data acquisition, computer programming, and control of actuators. The rigorous assessment protocol forces teams to remain on task and ensures course learning outcomes are met within the single semester timeframe. In the case of the MTR team, a grade of A was awarded as the rubrics used indicated a successful project, meeting all the learning outcomes. Feedback from the team, who are now working in industry, further illustrates the importance of this course in preparing them for successful engineering careers. Excerpts of their comments appear in Appendix C, highlighting how well the skills they learned in their capstone course translated to their industrial work environments. From the comments of students successfully completing the capstone course, it is apparent this capstone course directly prepares students for designing engineering systems in their post-graduation employment. 


\section{References}

1. Ward, T. A. (2013). Common elements of capstone projects in the world's top-ranked engineering universities. European Journal of Engineering Education, 38(2), 211-218. doi:10.1080/03043797.2013.766676

2. Systems Engineering Fundamentals., Ch. 11 Technical Reviews and Audits; App 16-a Schedules Defense Acquisition University Press, 2001

3. Agboola, O. P., Hashemipour, M., Egelioglu, F., Atikol, U., \& Hacisevki, H. (2012). Assessing a Decade Old Capstone Senior Projects Through ABET Accreditation Program Outcomes. Procedia - Social And Behavioral Sciences,47(Cyprus International Conference on Educational Research (CY-ICER-2012)North Cyprus, US0810 February, 2012), 120-125. doi:10.1016/j.sbspro.2012.06.624

4. Todd, R., \& Magleby, S. (2005). Elements of a successful capstone course considering the needs of stakeholders. European Journal Of Engineering Education, 30(2), 203-214. doi:10.1080/03043790500087332

5. HOTALING, N., FASSE, B. B., BOST, L. F., HERMANN, C. D., \& FOREST, C. R. (2012). A Quantitative Analysis of the Effects of a Multidisciplinary Engineering Capstone Design Course. Journal Of Engineering Education, 101(4), 630-656.

6. Inns, Simon. "Building a PIC18F USB Device." WFFwiki. N.p., 21 Nov. 2011. Web.

7. Olimex, "PIC-USB-4550 development board User’s Manual," https://www.olimex.com/Products/PIC/Proto/PIC-USB-4550/resources/PIC-USB-4550.pdf

8. BasicMicro, "B0097 - RoboClaw 2 Channel 15A Motor Controller Data Sheet,” RoboClaw 2x15A datasheet, 2010.

9. Microchip, “28/40/44-Pin, High-Performance, Enhanced Flash, USB Microcontrollers with nanoWatt Technology,” PIC18F4450 datasheet, 2006.

10. Microchip, “Microchip MPLABX IDE User’s Guide,” Microchip MPLABX IDE datasheet, 2011. http://ww1.microchip.com/downloads/en/DeviceDoc/50002027C.pdf

11. Albing, Bill. “Optimizing Web Applications with AJAX and Spread.” Code Project. N.p., 7 Nov 2006. http://www.codeproject.com/Articles/16272/Optimizing-Web-Applications-with-AJAX-and-Spread

12. "IG32P 24VDC 190 RPM Gear Motor with Encoder." IG32P 24VDC 190 RPM Gear Motor with Encoder. SuperDroid Robots, n.d. Web. 1 Feb. 2014.

13. MaxBotix Inc., “LV-MaxSonar-EZ1 High Performance Sonar Range Finder,” MB1010 datasheet, 2012.

14. Microchip, “14-Pin Flash-Based, 8-Bit CMOS Microcontrollers with nanoWatt Technology,” PIC16F688 datasheet, 2004. 


\section{Appendix A: Sample rubric matrices*}

\section{Class Participation}

\begin{tabular}{|c|c|c|c|c|c|}
\hline & $\mathbf{A}$ & B & C & D & $\mathbf{F}$ \\
\hline $\begin{array}{c}\text { Group } \\
\text { Dynamics }\end{array}$ & $\begin{array}{l}\text { All members work } \\
\text { well together. All } \\
\text { differences } \\
\text { resolved. } \\
\text { Everyone's } \\
\text { opinions are } \\
\text { respected. }\end{array}$ & $\begin{array}{l}\text { Group is } \\
\text { productive, but } \\
\text { not all members } \\
\text { carry equal } \\
\text { weight. }\end{array}$ & $\begin{array}{l}\text { Group is still } \\
\text { productive, but } \\
\text { there is noticeable } \\
\text { internal friction. } \\
\text { Some backbiting, } \\
\text { rude comments. }\end{array}$ & $\begin{array}{l}\text { Group performs } \\
\text { significantly } \\
\text { below potential. } \\
\text { Frequent } \\
\text { disrespect and } \\
\text { arguing. Extra } \\
\text { work sessions } \\
\text { required to } \\
\text { overcome team } \\
\text { member mistakes. }\end{array}$ & $\begin{array}{l}\text { Dysfunctional } \\
\text { group harboring } \\
\text { open hostilities, } \\
\text { with team } \\
\text { member(s) } \\
\text { contributing } \\
\text { essentially } \\
\text { nothing. No } \\
\text { tangible progress. }\end{array}$ \\
\hline $\begin{array}{c}\text { Personal } \\
\text { Contribution } \\
\text { (peer } \\
\text { assessment) }\end{array}$ & $\begin{array}{l}\text { All members are } \\
\text { equally productive } \\
\text { and knowledgeable } \\
\text { about all aspect of } \\
\text { the project. High } \\
\text { quality } \\
\text { communication of } \\
\text { knowledge to the } \\
\text { rest of the group. } \\
\text { Receptive of ideas } \\
\text { from others, } \\
\text { including } \\
\text { constructive } \\
\text { criticism. }\end{array}$ & $\begin{array}{l}\text { Some team } \\
\text { members are } \\
\text { less able to share } \\
\text { specialized } \\
\text { knowledge with } \\
\text { the rest of the } \\
\text { group. Still open } \\
\text { to input, and not } \\
\text { too critical of } \\
\text { the failures of } \\
\text { other team } \\
\text { members. }\end{array}$ & $\begin{array}{l}\text { Contributes } \\
\text { adequately to own } \\
\text { specialty but not } \\
\text { knowledgeable of } \\
\text { the other project } \\
\text { aspects. } \\
\text { Sometimes blames } \\
\text { other for failures. }\end{array}$ & $\begin{array}{l}\text { Cannot contribute } \\
\text { even to project } \\
\text { aspects } \\
\text { supposedly in } \\
\text { their specialty. } \\
\text { Will not give up } \\
\text { responsibility } \\
\text { even when } \\
\text { someone else can } \\
\text { do it! Mismatch } \\
\text { between } \\
\text { perceived and } \\
\text { actual abilities. }\end{array}$ & $\begin{array}{l}\text { Just occupies } \\
\text { space. Whatever } \\
\text { is done does not } \\
\text { contribute directly } \\
\text { to the actual } \\
\text { project. } \\
\text { A tragic waste. }\end{array}$ \\
\hline
\end{tabular}

* These rubric matrices are modified from those supplied courtesy of the Department of Mechanical and Aerospace Engineering at the University of Central Florida. 
Project Quality

\begin{tabular}{|c|c|c|c|c|c|}
\hline & A & B & C & D & $\mathbf{F}$ \\
\hline $\begin{array}{l}\text { Design } \\
\text { Report }\end{array}$ & $\begin{array}{l}\text { Clearly organized } \\
\text { and well- } \\
\text { documented. Every } \\
\text { detail and result } \\
\text { well explained. } \\
\text { Clear and concise, } \\
\text { and is easily } \\
\text { understandable a } \\
\text { neutral reader. }\end{array}$ & $\begin{array}{l}\text { Tolerably written, but } \\
\text { not particularly } \\
\text { elegant. Explanations } \\
\text { sometimes overly } \\
\text { complicated, split into } \\
\text { too many steps; or } \\
\text { possibly somewhat } \\
\text { under-commented. } \\
\text { Might be hard to } \\
\text { understand by a } \\
\text { neutral reader, but the } \\
\text { author can } \\
\text { communicate verbally } \\
\text { what he/she meant. }\end{array}$ & $\begin{array}{l}\begin{array}{l}\text { Definitely under- } \\
\text { commented, with many } \\
\text { numbers appearing } \\
\text { without justification. }\end{array} \\
\text { Almost impossible for } \\
\text { an outsider to } \\
\text { understand, most likely } \\
\text { because the author } \\
\text { does not understand it } \\
\text { well himself/herself. }\end{array}$ & & $\begin{array}{l}\text { Completely } \\
\text { unintelligible. } \\
\text { May contain } \\
\text { incomplete or } \\
\text { under-designed } \\
\text { parts. Misleading } \\
\text { or incorrect data. }\end{array}$ \\
\hline $\begin{array}{l}\text { Prototype } \\
\text { Construction }\end{array}$ & $\begin{array}{l}\text { Sturdy and robust } \\
\text { with a high degree } \\
\text { of craftsmanship. } \\
\text { Appropriately uses } \\
\text { modular design. } \\
\text { Well-built and } \\
\text { elegant. }\end{array}$ & $\begin{array}{l}\text { Everything works for } \\
\text { the most part, but it } \\
\text { has some elements } \\
\text { work but are not } \\
\text { pretty. There is still } \\
\text { excellent } \\
\text { craftsmanship. } \\
\text { Well-built but } \\
\text { somewhat inelegant. }\end{array}$ & $\begin{array}{l}\text { Positives are equally } \\
\text { weighted by negatives. } \\
\text { Some elements are } \\
\text { properly handled and } \\
\text { others seem to be } \\
\text { ignored entirely. } \\
\text { May work sporadically } \\
\text { or only for a short } \\
\text { period of time. } \\
\begin{array}{l}\text { Either elegant ideas } \\
\text { poorly executed, or } \\
\text { else a slick-looking } \\
\text { doorstop. }\end{array}\end{array}$ & & $\begin{array}{l}\text { No evidence of } \\
\text { improvement or } \\
\text { learning from } \\
\text { past mistakes. } \\
\text { Appears as if all } \\
\text { time spent on the } \\
\text { project was a } \\
\text { waste of time. } \\
\text { The results are an } \\
\text { embarrassment. }\end{array}$ \\
\hline
\end{tabular}




\section{Appendix B: Sample presentation evaluation rubric}

\section{Final Presentation Evaluation}

\section{Team:}

\begin{tabular}{|c|c|c|}
\hline Subject & Score & Comments \\
\hline $\begin{array}{l}\text { 1. Project/System/Team Overview \& Major Works for the } \\
\text { Project: clear introduction of the project }\end{array}$ & $/ 5$ & \\
\hline $\begin{array}{l}\text { 2. Design Requirements \& Specifications: technical goals } \\
\text { \& minimum success criteria }\end{array}$ & $/ 5$ & \\
\hline $\begin{array}{l}\text { 3. Trade Study \& Verification Approach/plan: technical } \\
\text { justifications }\end{array}$ & $/ 5$ & \\
\hline $\begin{array}{l}\text { 4. System Development: } \\
\text { 1) Overview of system completed } \\
\text { 2) Drawings/circuit diagrams } \\
\text { 3) Analysis/simulation \& test results } \\
\text { 4) Bills of Materials \& Budget } \\
\text { 5) Prototype \& its demonstration: what will be shown? } \\
\text { A short movie if possible. }\end{array}$ & $/ 20$ & \\
\hline $\begin{array}{l}\text { 5. Conclusions: } \\
\text { 1) Achieved \& Lessons learned } \\
\text { 2) Future improvements/optimization }\end{array}$ & $/ 5$ & \\
\hline Any Bonus or Penalty: Technical quality \& coverage & & \\
\hline TOTAL & $/ 40$ & \\
\hline Overall Comments: & & \\
\hline
\end{tabular}

Evaluator: 


\section{Appendix C: Comments from former MTR team members now working in industry and the linked course learning outcome(s)}

- "After all the ideas are made known, team members then collaborate with each other to find the best possible solution. This approach may take more time but it provides the team with a wide range of ideas from each team member, and it is also serves as team building time as well [c].”

- "We worked collaboratively both by meeting in person within campus project rooms, and virtually using Google chat sessions and screen sharing. Meetings for which the primary topic would be for organizing and delegating tasks, or for preparing content for presentation and reports, were held virtually simply due to scheduling constraints [c, f].”

- "Use of the MPLAB programming environment was learned by following enthusiastic tutorials published on the web. Then, with this basis, it became easier to review microchips' own application programming examples intended to be used with MPLAB. The weekly team meetings provided opportunities to share what was learned in using MPLAB with the rest of the team [g]. ”

- $\quad$ The trade studies performed for the project helped in professional readiness. I have frequently performed such comparisons when selecting components such as servo motors and controllers [b]. "

- "All of the members of the group brought different skill sets to the project. This was a benefit as it bought several viewpoints. Working in an engineering field requires much of the same collaboration [c].”

- "I have found the design process for this project to have reflected actual engineering design progressions in professional experience since graduation $[\mathrm{a}, \mathrm{b}]$. This class was valuable not so much for the technical skills practiced, but in gaining a level of experience and trust in the structured design process as a tool to decompose a complex problem into a finite set of specifications and tasks that members of a team could accomplish [d]. Having this experience has allowed me to more seamlessly involve myself in the design team of an active organization. Being already familiar with the general process, I could focus on the technical challenges of the project rather than the process.

- $\quad$ "This class very closely mimics the professional engineering design process [a]. Just as with this class project, professionally, I have started with thorough trade studies, and worked iteratively towards a final product [d]. A major component of the project was working collaboratively with other engineers, being able to take their expertise and use it towards the betterment of the project [g].”

- "One of the additional skills that I was able to cultivate through the process of this project was proper documentation [f]. Each group member was responsible for documenting their work throughout the semester, and the notes that were kept collected as part of the overall class grade.”

- " "[the instructor] is very strict about being professional and ethical during the course of this class, and one of his major points is to be prompt ... thus we learned to take project management seriously. It reflects on all of us as a team, just as can be expected in the professional world [e].”

- "We learned that it is better to test our components and prototype for all possible scenarios; there is uncertainty waiting to happen especially in the last few weeks of the project [b].”

- "I think that having such a rigorous grading rubric for each section of the project ensured the attention to detail that is needed in the professional world. After this project, I can approach and participate on teams working on bigger capital projects [e].” 